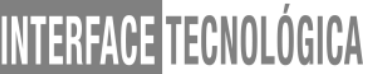

\section{FORMAS DE UTILIZAÇÃO DOS DEJETOS DE SUÍNOS}

\author{
WAYS OF USING SWINE MANURE
}

\author{
Tatiane Oliveira Mortari - tatiane_oliveira5@hotmail.com \\ Marcela Midori Yada - marcelayada@gmail.com \\ Faculdade de Tecnologia de Taquaritinga (FATEC) - SP - Brasil \\ DOI: 10.31510/infa.v15i2.481
}

\begin{abstract}
RESUMO
Com este estudo se objetiva analisar conceptualmente pontos pertinentes aos dejetos ou rejeitos oriundos das criações de suínos. De modo que, os suinocultores devem se preocupar com a gestão dos resíduos sólidos e com os impactos da atividade de criação de suínos, tanto quanto devem se preocupar com a engorda dos animais e com a comercialização do animal in natura ou já abatido. O presente estudo analisa a questão do ponto de vista econômico e social, citando dados que comprovam o potencial de negócio que há no dejeto suíno, principalmente do ponto de vista de usá-lo para produzir a bioenergia, proveniente deste e de outros materiais residuais, que também podem ser usados como material de biodigestores, além de mencionar demais aplicações e usos. Isto indica que além de ser uma excelente forma de mitigar os danos ambientais das suinoculturas, as atividades econômicas provenientes dos rejeitos dos suínos acarretam novas perspectivas de desenvolvimento econômico e de geração de energia alternativa.
\end{abstract}

Palavras-chave: Esterco suíno. Economia Sustentável. Reuso. Redução de Danos Ambientais.

\begin{abstract}
This study aims to analyze, as if they said superficially, all the pertinent aspects of manure (and the manure or tailings) from pig farms. So, the pig farmers should be concerned about Solid Waste Management and the impacts of hog rearing activity, as well as concern for fattening animals and the commercialization of the animal in natural or already slaughtered. This present paper analyzes the issue from an economic and social point of view, citing data that bought the business potential of swine manure; mainly from the point of view of using it to produce bioenergy from this and other waste materials (which can also be used as bio digesters material - the process or equipment that transforms the pig waste into energy, for example), as well as mentioning other applications and uses. This is a qualitative literature review, which is devoted to analyzing the ways of disposing of waste from pigs, especially in the case of biogas. The result is that besides being an excellent way to mitigate the environmental damages of pig farms, the economic activities of pig rejects bring new prospects of economic development and alternative energy generation.
\end{abstract}

Keywords: Pig manure. Sustainable Economy. Reuse. Reduction of Environmental Damage 


\section{WNTERPHESTECENOLOGGCA}

\section{INTRODUÇÃO}

As atividades de criação de suínos são intensas e encontram-se em expansão no país, seja pela aceitação cultural (e culinária) da carne de porco, ou mesmo pelas diversas aplicações dos suínos que são encontradas na sociedade, como aplicações industriais ou mesmo de geração de fontes alternativas de energia renovável, entre outras.

Os dejetos de animais são responsáveis por $20 \%$ das emissões de gases poluentes na atmosfera, um número altamente significativo, quando comparado às indústrias, que representam 32\% das emissões (KONZEN, 2005).

Nas sociedades sustentáveis, mesmo um típico problema, como o esterco de suínos, que é muito danoso ao meio ambiente, pode se tornar matéria prima para outras indústrias (SILVA; FRANÇA; OYAMADA, 2015). O impacto ambiental causado pelo manejo inadequado dos dejetos líquidos de suínos tem causado severos danos ao meio ambiente.

Segundo Higman e Burgt (2003), biomassa é todo e qualquer combustível ou matéria bruta derivada de organismos que estiveram vivos recentemente, e isso inclui culturas alimentares, gramíneas e plantas lenhosas, resíduos da agricultura e silvicultura, algas ricas em óleo, e ainda, componentes orgânicas de resíduos urbanos e industriais (NREL, 2012).

Sendo assim, a biomassa produzida é um elemento essencial para o ser humano, principalmente na atual sociedade, utilizado como combustível no meio rural, visto que é uma alternativa eficaz de produção e distribuição de energia (PEREIRA et al., 2015).

Entre as mais importantes formas de se converter a biomassa destas criações, ou os dejetos, em energia, há então os processos físicos de classificar, secar, comprimir e fragmentar para realizar a combustão direta ou a queima, além de ainda haver os processos termoquímicos e os processos biológicos (ANEEL, 2005).

O armazenamento em lagoas ou depósitos abertos minimiza a poluição dos dejetos de suínos pois favorecem a produção de gases nocivos, contaminações de recursos naturais e interferem na qualidade de vida nos grandes centros produtores de suínos (KONZEN, 2005).

A estabilização dos dejetos de suínos por meio de biodigestores anaeróbicos é importante em função dos aspectos sanitários, com potencial na geração de energia renovável, além de oferecer condições econômicas de reciclagem de materiais orgânicas e de nutrientes (KONZEN, 2005).

Os processos biológicos que fazem a conversão energética do esterco suíno em biomassa, se dão prioritariamente por meio de duas formas: a técnica de digestão anaeróbia e a técnica de fermentação. 


\section{WWTEPARESTEENOLOGGCA}

A biodigestão anaeróbica possui vantagem da produção de biogás (metano) além da redução de odores, eliminação de patógenos, redução da demanda bioquímica de oxigênio (DBO), produção de biofertilizante, baixa produção de lodo, baixos custos operacionais e de investimento e possibilidade de sistemas descentralizados de tratamento de dejetos (OLIVEIRA, 2014).

Além disto, outras aplicações incluem ainda a transformação dos dejetos das criações suínas em um substrato, que pode ser usado como fertilizante ou mesmo como base de cultivo de algumas culturas vegetais.

Sobre a metodologia do estudo, trata-se de uma pesquisa bibliográfica, e de metodologia qualitativa; que tem como material referencial teórico os estudos publicados em artigos científicos, ou os trabalhos acadêmicos, ou ainda o material publicado em periódicos e em livros. Os materiais pesquisados são bibliografias recentes e de grande importância na área do assunto abordado.

O estudo se justifica pela quantidade de material residual que as criações de suínos fazem, e busca possíveis soluções à problemática ambiental, apontando novas destinações e novas aplicações e usos para os materiais poluentes já conhecidos nos meios rurais.

O objetivo deste artigo é analisar quais as opções de uso para os dejetos das criações de suínos, de modo a mitigar ou eliminar os impactos ambientais das atividades pecuárias suínas. Avaliar e comparar as duas técnicas principais de destinação de rejeitos de criações de suínos pelo uso de biodigestor, usado como fonte de energia alternativa e a biomassa, resultante deste processo. Além de demonstrar demais aplicações do esterco suíno.

\section{DEJETOS DA CRIAÇÃO DE SUÍNOS: CONCEITO, CARACTERIZAÇÃO E APLICAÇÕES.}

De acordo com Oliveira (1993), a suinocultura brasileira constitui-se de uma atividade de pequenas propriedades rurais, e isto desde a década de 1980.

Os maiores produtores de suínos do Brasil, mais uma vez, desde a década de 80 do século XX são os estados da região Sul.

Segundo Oliveira (1993), a suinocultura é uma atividade fundamental para o estado de Santa Catarina, tanto em termos econômicos, como sociais e possui 3,35 milhões de cabeças suínas, o que representa $11,2 \%$ do rebanho nacional.

SENAI (2016) fez um importante estudo sobre o potencial bioenergético do estado do paraná e concluiu que as origem de bioenergia podem vir das atividades de pecuária ou álcool 


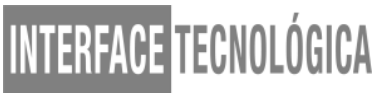

e açúcar, além da produção de vegetais não lenhosos e vegetais lenhosos e de demais potenciais áreas dos setores industrial e agroindustrial, como laticínios, produtos cítricos, abatedouros e frigoríficos, cervejarias e micro cervejarias e resíduos provenientes das varrições e podas urbanas.

Todo este potencial exponencial de exploração de geração de bioenergia que o estado do Paraná tem, é observado em razão da forte atividade agroindustrial que a região tem; e certamente a produção de suínos tem um papel de destaque neste cenário agrário do estado do Paraná, e da região sul do Brasil.

Mas, outros estados, como o sudeste, principalmente Minas Gerais e São Paulo, também têm excelentes atividades agrícolas e vasto potencial de exploração de bioenergia; ou de aumento da poluição, se os destinos corretos de criação de suínos não forem dados, por exemplo, e os resíduos forem lançados indiscriminadamente ao meio ambiente, desta forma, causam um impacto negativo com a atividade de criação suína, gerando mais poluição com a ampliação da produção dessa atividade.

Então, trata-se de uma questão complexa, que exige reflexão, atenção e ação, tanto por parte de autoridades, produtores, ou por parte de pesquisadores ou pessoas de meios acadêmicos.

Conforme já foi afirmado, a produção de suínos exige cuidados na gestão de resíduos, porque os impactos ambientais desta atividade são muito intensos.

As criações de suínos causam muitos dejetos, e eles pode ultrapassar a marca de 1000 $\mathrm{kg}$ de material residual, gerado por ano para cada animal criado (WIKIFARMER, 2017).

Manter a propriedade limpa é a chave para criar animais saudáveis e prósperos. Devese diariamente remover os resíduos dos abrigos e celeiros dos suínos, porque eles atraem moscas e insetos. Durante o calor do verão, é benéfico colocar um ventilador dentro de abrigos ou galpões dos suínos para promover uma boa ventilação e diminuição dos odores. Os suinocultores devem analisar as maneiras como eles podem aproveitar os resíduos dos animais. Eles podem usá-los como fertilizantes na agricultura, doá-los a uma união de agricultores locais ou vendê-los aos comerciantes locais.

Estima-se que um animal de tamanho médio de $50 \mathrm{~kg}$ irá produzir esterco pesando 720 $\mathrm{kg}$ em um ano. Se o agricultor adicionar, também, resíduos de alimentos, os resíduos anuais totais de apenas um animal de tamanho médio pode exceder $1000 \mathrm{~kg}$. Consequentemente, deve-se construir, antecipadamente, uma política de gestão de resíduos que seja compatível, sustentável e ambientalmente amigável (WIKIFARMER, 2017). 


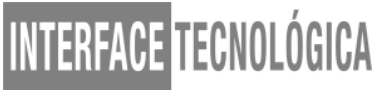

Segundo Rohr (2014), toda suinocultura requer um programa racional de controle de dejetos, para sua correta utilização, constituído de seis etapas: produção, coleta, armazenagem, tratamento, distribuição e utilização dos dejetos, podendo ser na forma sólida, líquida ou pastosa. De forma geral, estima-se que a produção de dejetos de suínos seja de 100L/matriz/dia em uma granja de ciclo completo, de $60 \mathrm{~L} / \mathrm{matriz} /$ dia em granjas produtoras de leitão e de 7,5 L/cabeça/dia em granjas de produção de terminados. Contudo, o tratamento de dejetos, para cumprir seu objetivo final e ser efetivo, necessita converter os dejetos em material seguro ao manuseio e com menor potencial poluidor ao meio ambiente.

\section{PROCEDIMENTOS METODOLÓGICOS}

\subsection{Biodigestores}

Os biodigestores são equipamentos que concentram as atividades de biodigestão Figura 1). A biodigestão por sua vez é a fermentação ou a degradação anaeróbia de material orgânico, por meio de ação de microrganismos (SENAI, 2016)

\begin{abstract}
A biodigestão ou fermentação, constitui o nome popular dado ao processo de degradação anaeróbia de matéria orgânica, por meio da ação de diversos microrganismos. Os produtos finais são gases, certa quantidade de energia (calor) e nova biomassa (lodo digerido). A mistura gasosa formada contém metano (50-75\%), gás carbônico (25-50\%) e pequenas quantidades de hidrogênio, sulfeto de hidrogênio, amônia e outros gases, bem como umidade. A composição dos produtos finais recebe influência, principalmente, dos substratos utilizados na produção dessa mescla, em virtude da técnica de fermentação empregada e das diferentes tecnologias de construção dos biodigestores e das usinas (SENAI, 2016, p. 51).
\end{abstract}

Assim, observa-se que a biodigestão gera principalmente dois produtos principais, a energia, o calor e a nova biomassa, além disto, gera outras decomposições, como os gases, tal como a amônia, o hidrogênio e a umidade.

E o uso de dejetos de suínos para gerar energia é tão importante tanto para o equilíbrio ambiental e sustentabilidade, tanto quanto para o mecanismo de desenvolvimento limpo (MDL).

O MDL pode ser usado para financiar projetos ambientais, ou pode ser usado para agregar valores de empresas em mercados e capitais abertos ou em bolsas de valores. E isto quer dizer que, o estrume de suínos pode ser usado para gerar riquezas, para diminuir a problemática social e para equilibrar o meio ambiente, simultaneamente. 
Neste sentido, Rohr (2014) diz que o MDL é responsável por promover principalmente, o desenvolvimento sustentável.

O MDL implica assumir responsabilidade para reduzir as emissões de poluentes e promover o desenvolvimento sustentável. É um mecanismo de investimentos pelo qual os países desenvolvidos têm metas de redução, emissão e aplicação de recursos financeiros em projetos que venham a reduzir a emissão de gases do efeito estufa. Está diretamente ligado ao tratamento racional e adequado dos dejetos e tem como consequência menor risco ambiental, redução de custos (utilização do gás produzido) e geração de renda para o produtor (integração lavoura e pecuária, venda de adubo orgânico) (ROHR, 2014, p. 823-824).

Figura 1: Biodigestor.

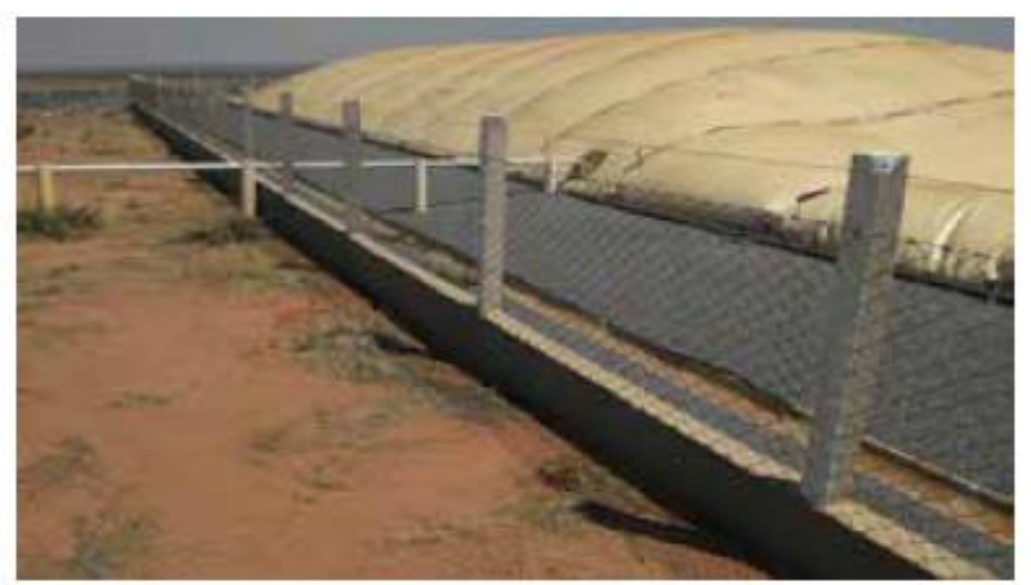

Fonte: ROHR (2010).

Assim, os biodigestores, juntamente com os estercos de criações de suínos e outros materiais, são os protagonistas de um desenvolvimento mais verde, sustentável e bom economicamente para ambas os agentes envolvidos nesta questão (Figura 1).

Uma das maneiras mais eficazes de se avaliar as potencialidades de tal energia renovável em território brasileiro é focar no desempenho dos principais setores econômicos, nos planos estaduais e nacional, e que são adequados para originar efluentes ou resíduos apropriados à biodigestão. Nesse sentido, os segmentos agropecuário, agroindustrial, industrial e urbano são os que mais se destacam (SENAI, 2016).

\section{RESULTADOS E DISCUSSÃO}

\subsection{Outros usos para o esterco suíno e suas relações com a sustentabilidade}

O esterco suíno de fato pode representar a renda extra para os produtores de suínos, ou seja, algo que algum tempo atrás era tido como um problema ou material poluente, pode, 
ultimamente, ser usado para gerar outros produtos e outras fontes de renda. Isto é ecologicamente correto, e ainda ajuda nos fatores da problemática social.

Oliveira; Santos Filho (2014), em estudo sobre a composição da renda total as atividades suinícolas, afirma que o esterco pode representar uma fonte de renda forte para os produtores de suínos.

$\mathrm{Na}$ atividade suinícola as receitas são provenientes principalmente da venda de animais para abate ou para engorda e descarte de animais de reprodução. Em alguns casos, o esterco produzido pode ser uma fonte de renda quando existir mercado efetivo para ele ou em casos em que a transferência interna do esterco como fertilizante represente uma economia na compra de insumos (custo de distribuição menor que o valor fertilizante) (OLIVEIRA; SANTOS FILHO, 2014).

Oliveira; Santos Filho (2014) não focaram tanto na questão dos biodigestores e da energia verde (alternativa) ou da biomassa, que também são produtos do esterco de suínos. O fertilizante usado como adubo, também é uma boa opção para quem compra, porque sai mais barato do que os fertilizantes vendidos em lojas convencionais (OLIVEIRA; SANTOS FILHO, 2014).

Assim, há no mínimo três produtos que podem ser obtidos por meio do esterco de suínos: o esterco natural, seco e tratado, com algumas aplicações de correções físicoquímicas; os biodigestores, que transformam o esterco suíno em energia alternativa ou em nova biomassa; além das aplicações de uso como fertilizantes e outros produtos, tais como os gases e demais materiais, que resultam da biodigestão.

O biodigestor também tem duas aplicações distintas, além da biomassa resultante do processo que ocorre no biodigestor, que são a produção de energia biogás e a energia bioelétrica (biometano) (SENAI, 2016).

De acordo com Senai (2016), o Brasil processa mais de 3,03 milhões de toneladas de carne suína por que produzem mais de 39 milhões de rejeitos por ano. Tendo ainda um potencial de produzir 340 milhões de $\mathrm{m}^{3}$ (metros cúbicos) de potencial de biogás ou um potencial energético de $486 \mathrm{GWh} /$ ano (Giga Watts/hora), apenas com a produção de suínos, sendo que este potencial não é tão aproveitado (Tabela 1). 
Tabela 1: Dados sobre a produção de biogás e bioeletricidade a partir da biodigestão dos resíduos resultantes do abate e do processamento de carnes provenientes de bovinos, suínos e frangos de corte, em comparativo do âmbito de Brasil com o cenário do Paraná.

\begin{tabular}{|c|c|c|c|c|c|c|}
\hline & $\begin{array}{c}\text { Setor } \\
\text { Industrial }\end{array}$ & $\begin{array}{c}\text { Produçăo } \\
\text { Anual Carne } \\
\text { Processada }(t)^{*}\end{array}$ & $\begin{array}{c}\text { Produçăo } \\
\text { Anual de } \\
\text { Residuos }\left(\mathrm{m}^{3}\right)^{\mathrm{h}}\end{array}$ & $\begin{array}{l}\text { Potencial de } \\
\text { Biogás }\left(\mathrm{m}^{3}\right)^{2}\end{array}$ & $\begin{array}{c}\text { Potencial } \\
\text { Energético } \\
\text { (GWh/ } \\
\text { ano) }\end{array}$ & $\begin{array}{c}\text { Relaçâo } \\
\text { PR/BR em } \\
\text { produçăo } \\
\text { de energia }\end{array}$ \\
\hline \multirow{3}{*}{$\frac{\sqrt{2}}{\frac{2}{2}}$} & Bovinos & $497.084,50$ & $6.462 .098,50$ & $55.444 .805,13$ & 79,29 & 4,20 \\
\hline & Suinos & $590.426,10$ & $7.675 .539,30$ & $66.393 .414,95$ & 94,94 & 19,50 \\
\hline & Frangos de Corte & $3.863 .517,37$ & $50.225 .725,81$ & $396.783 .233,90$ & 567,40 & 30,30 \\
\hline \multirow{3}{*}{ क्ष } & Bovinos & $11.862 .879,00$ & $154.217 .427,00$ & $1.323 .185 .523,66$ & $1.892,16$ & \\
\hline & Suinos & $3.027 .802,95$ & $39.361 .438,35$ & $340.476 .441,73$ & 486,88 & \\
\hline & Frangos de Corte & $12.759 .627,90$ & $165.875 .162,70$ & $1.310 .413 .785,33$ & $1.873,89$ & \\
\hline
\end{tabular}

Fonte: SENAI (2016).

Legenda: A) ABIEC, MAPA, 2014b; B) ROSENWINKEL; AUSTERMANN-HAUN; MEYER, 2005. Índice de conversão: $13 \mathrm{~m}^{3}$ efluente/tcarne.processada; C) ROSENWINKEL, AUSTERMANN-HAUN; MEYER, 2005. Índice de conversão: 8,58 $\mathrm{m}^{3}$ biogás/tcarne.de.boi; $8,65 \mathrm{~m}^{3}$ biogás/tcarne.de.porco; 7,9 $\mathrm{m}^{3}$ biogás/tcarne.de.ave; D) SGANZERLA, 1983. Índice de conversão de biogás em energia de 1,43

$\mathrm{kWh} / \mathrm{m}^{3}$ - SENAI (2016)

Deste modo, fica evidente perceber o campo de exploração que o Brasil, e principalmente as regiões Sul e Sudeste, têm em se tratando de produtos obtidos a partir do rejeito da produção de suínos, com enfoque para o potencial de produção de energia, e o uso de biodigestores.

A produção de biomassa já encontra certo mercado dentro da economia agrária brasileira; e a tendência é de crescimento latente, principalmente, ao se tomar como exemplo situações como a encontrada em estados do Sul, como o Paraná, onde nota-se que $20 \%$ da relação de produção de energia que existe entre estados do Sul, no caso especificamente o Paraná, é devido às atividades da suinocultura (Tabela 2).

Evidentemente este valor é tímido, haja a vista a grandiosidade que o mercado suíno representa, hoje, no mercado nacional. Assim, o que se nota é a subutilização que os rejeitos dos suínos. Mas as possibilidades de aplicações que técnicas como os biodigestores - e que são usados para processar os rejeitos dos suínos - permitem que se sejam feitas, abrem, então, novas formas de exploração econômica, e ainda garantem que os danos ambientais das suinoculturas sejam atenuados ou drasticamente reduzidos.

Neste sentido, e em rumo a sustentabilidade e ao desenvolvimento do país, o Brasil deve se atentar ao fato de esforçar-se para aproveitar ao máximo as técnicas de reuso ou reaproveitamento, criação de subprodutos, e etc. 


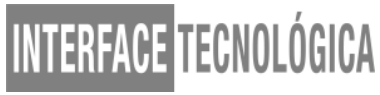

O estado de São Paulo é um dos líderes na produção de biomassa, representando $44 \%$ da produção nacional de biomassa, ao passo que estados do Sul, como o Paraná e Rio Grande do Sul, juntos, correspondem a 6\% da biomassa do país (SENAI, 2016).

Tabela 2: Dados sobre biomassa: potencial instalado e em operação de produção de biomassa por regiões do país.

\begin{tabular}{c|c|c}
\hline Estado & Potência Fiscalizada (kW) & \% nacional \\
\hline SP & 5.469 .408 & $44,0 \%$ \\
\hline MG & 1.378 .375 & $11,0 \%$ \\
\hline MS & 1.242 .547 & $10,0 \%$ \\
\hline GO & 1.070 .300 & $9,0 \%$ \\
\hline PR & $\mathbf{6 5 2 . 8 9 5}$ & $\mathbf{5 , 0} \%$ \\
\hline BA & 520.245 & $4,0 \%$ \\
\hline PE & 297.584 & $2,0 \%$ \\
\hline AL & 290.662 & $2,0 \%$ \\
\hline MA & 284.400 & $2,0 \%$ \\
\hline ES & 231.500 & $2,0 \%$ \\
\hline MT & 212.132 & $2,0 \%$ \\
\hline RS & 149.605 & $1,0 \%$ \\
\hline SC & 141.791 & $1,0 \%$ \\
\hline Outros & 399.748 & $3,0 \%$ \\
\hline TOTAL & 12.341 .192 & $\mathbf{1 0 0 , 0} \%$ \\
\hline
\end{tabular}

Fonte: SENAI (2016, p. 25)

Evidentemente estes dados incluem toda a biomassa gerada, mas considerando-se apenas os rejeitos da criação de suínos, há muito espaço para crescimento deste mercado, uma vez que existe ainda um certo desconhecimento em relação ao potencial de utilização dos rejeitos das suinoculturas.

\section{CONSIDERAÇÕES FINAIS}

Além do meio ambiente, os produtores de suínos se beneficiam com a correta destinação dos rejeitos dos suínos e a economia sai fortalecida. Isto porque os novos mercados das bolsas de valores já se interessam por iniciativas produtivas que tenham enfoque em atividades econômicas mais verdes e mais sustentáveis. 
Com iniciativas que visam o reuso ou a destinação correta dos rejeitos das atividades de suinoculturas, abrem-se novas possibilidades de empregos, diminuindo os danos ambientais contribuindo para o desenvolvimento e preservação das sociedades e do planeta.

\section{REFERÊNCIAS}

Associação Brasileira de Criadores de Suínos - ABCS. Produção de suínos: teoria e prática. Coordenação editorial: Associação Brasileira de Criadores de Suínos; Coordenação Técnica da Integrall Soluções em Produção Animal. Brasília (DF): ABCS, 2014. 908p.: il. : color. Compilação - Texto de vários autores. Versão online. Disponível em < http://www.abcs.org.br/attachments/1823_ Livro\%20Produ\%C3\%A7\%C3\%A3o.pdf > Acesso em 14 de jun. 2018.

Agência Nacional de Energia Elétrica - ANEEL. Atlas de Energia Elétrica. 2 ed. 2005. Disponível em: <http://www.aneel.gov.br/ aplicacoes/Atlas/download.htm>. Acesso em 12 jun. 2018.

HIGMAN, C.; BURGT, M. Van Der. Gasification, Gulf Professional Publishing: Feedstocks and Feedstock Characteristics. Elsevier Science, 1 ed., cap. 4, Burlington, MA, USA, 2003.

KONZEN, E. A. Dejetos de suínos fermentados em biodigestores e seu impacto ambiental como insumo agrícola. In: Simpósio Goiano De Suinocultura, 2., 2005, Goiânia. Seminários técnicos de suinocultura. Goiânia: Avesui Centrooeste, 2005. p. 56 - 64.

MOLENA, J. Resposta Do Capim Braquiária À Aplicação De Cama De Frango E Saturação Por Bases Em Argissolo Vermelho Amarelo Distrófico - na região de Taquaritinga-SP. Taquaritinga: ITES, 2016. Trabalho apresentado ao Departamento de Agronomia do Instituto Taquaritinguense de Ensino Superior "Dr. Aristides de Carvalho Schlobach”, 2016. Orientador: Prof. Dr. Juan Gabriel Cristhoffer Lopes Ruiz.

NATIONAL RENEWABLE ENERGY LABORATORY - NREL. Biomass Energy Basics. Washington, 2012. Disponível em: <http://www.nrel.gov/learning/re_biomass.html >. Acesso em: 28 maio 2018.

OLIVEIRA, P. A. V. (coord.) Manual de manejo e utilização dos dejetos de suínos. Concórdia: EMBRAPA-CNPSA, 1993, 188p. EMBRAPA-CNPSA, Documentos, [n. $\left.{ }^{\circ}\right] 27$.

OLIVEIRA, V.F.de; SANTOS FILHO, J.I. dos. Indicadores econômicos e custo de produção em suinocultura. In ABCS - Associação Brasileira de Criadores de Suínos Produção de suínos: teoria e prática. Coordenação editorial: Associação Brasileira de Criadores de Suínos; Coordenação Técnica da Integral Soluções em Produção Animal. Brasília (DF): ABCS, 2014. 908p.: il.: color. Compilação - Texto de vários autores. Versão online. Pp. $178-187$.

PEREIRA, M. S.; GODOY, T. P.; GODOY, L. P.; BUENO, W. P.; WEGNER, R. S. Cálculo do Potencial Energético com Dejetos de Bovinos e Suínos do Departamento de Zootecnia da UFSM. XXXV Encontro Nacional de Engenharia De Produção: Perspectivas Globais para a Engenharia de Produção Fortaleza (CE), de 13 a 16 de outubro de 2015, pp. 1-15. 
Disponível em < http://www.abepro.org.br/biblioteca/ TN_WIC_214_268_26668.pdf> Acesso em 12 de jun. de 2018.

ROHR, S. A. Biodigestores, créditos de carbono e mecanismo de desenvolvimento limpo (MDL). In ABCS - Associação Brasileira de Criadores de Suínos -. Produção de suínos: teoria e prática. Coordenação editorial: Associação Brasileira de Criadores de Suínos; Coordenação Técnica da Integrall Soluções em Produção Animal. Brasília (DF): ABCS, 2014. 908p.: il. : color. Compilação - Texto de vários autores. Versão online.

SENAI (Serviço Nacional de Aprendizagem Industrial - PR); FIEP (Federação das Indústrias do Estado do Paraná). Oportunidades da Cadeia Produtiva de Biogás para o Estado do Paraná - Curitiba: Senai/PR. 2016.

SILVA, C. M.; FRANÇA, M. T. de; OYAMADA, G. C. Características da Suinocultura e Os Dejetos Causados ao Ambiente. Rev. Connection Line, n.12 - pp. 44-59, 2015. Revista Eletrônica da Univag. Disponível em <http://www.periodicos.univag.com.br/index. php/CONNECTIONLINE/article/viewFile/199/453> Acesso em 16 de jun. de 2018.

WIKIFARMER (Equipe Editorial). Produção de estrume de porco e gestão de resíduos. 2017. Disponível em <https://wikifarmer.com/pt-br/producao-de-estrume-de-porco-e-gestaode-residuos-e-gestao-de-residuos/> Acesso em 10 de jun. de 2018. 